Revista Temas Socio Jurídicos

Vol. 37 No 75 Julio - Diciembre de 2018

pp. $68-91$

ISSN: 0120-8578

ISSN electrónico: 2590-8901

\title{
LA JURISPRUDENCIA DE LA CORTE SUPREMA DE JUSTICIA DE \\ COLOMBIA SOBRE EL MALTRATO ENTRE EX PAREJAS SENTI- MENTALES: ANÁLISIS DESDE LOS ESTUDIOS DE GÉNERO ${ }^{1 *}$
}

Jeniffer Forero Laguado ${ }^{2 *}$

Recibido: Noviembre 3 de 2018

Aprobado: Diciembre 1 de 2018

\section{RESUMEN}

Este artículo analiza el tema de la violencia provocada entre ex parejas y la forma como se aborda por la jurisprudencia colombiana, desde un enfoque de género, con el fin de examinar si se presenta una discriminación de género en los argumentos de la jurisprudencia vigente de la Sala de Casación Penal de la Corte Suprema de Justicia en materia de violencia intrafamiliar, cuando el maltrato denunciado se presenta entre ex parejas. Para realizar este estudio, en primer lugar se describirá algunas causas, estereotipos y manifestaciones de este tipo de violencia de género, se explicará también los ciclos de violencia de pareja, las dificultades que implica romper este ciclo, aunque la relación sentimental termine y las causas y eventos de la retractación. En segundo término, se identificarán los argumentos de la Corte ofrecidos en casos en que estudió esta problemática, y posteriormente, se examinaran desde una perspectiva de género, para determinar si existen criterios sospechosos de discriminación de género.

Palabras clave: Género, ex parejas, jurisprudencia, violencia intrafamiliar.

$1^{*}$ Artículo de investigación como requisito de grado de la Maestría en Derecho de Familia de la UNAB

$2^{* *}$ Abogada egresada de la UIS. Especialista en Derecho de Familia de la UNAB. Especialista en Derecho Procesal de la U. Santo Tomas de Bucaramanga. Candidata a Magister en Derecho de Familia de la UNAB. jenflaguado@hotmail.com 


\title{
THE JURISPRUDENCE OF THE SUPREME COURT OF JUSTICE OF COLOMBIA ON THE MALTREATMENT BETWEEN FORMER COUPLES: ANALYSIS FROM GENDER STUDIES
}

\begin{abstract}
This article studies the issue of violence produced between former couples and the way it is addressed by Colombian jurisprudence, from a gender perspective, in order to examine whether gender discrimination exists within the arguments of the current jurisprudence of the Criminal Cassation Chamber of the Supreme Court of Justice in matters of interfamily violence, when the reported abuse is testified by ex-partners. To carry out this study, we will first describe some causes, stereotypes and manifestations of this type of gender violence, we will also explain the cycles of partner violence, the difficulties that arise while trying to break this cycle, even if the relationship ends, and the causes and events that lead the victim to take back or change their testimony in order for the abuser to avoid being prosecuted. Secondly, the arguments that the Court has offered while studying this issue will be identified, and subsequently, they will be examined from a gender perspective to determine if there are suspicious criteria of gender discrimination.
\end{abstract}

Key Words: Gender, former couples, jurisprudence, interfamily violence.

\section{A JURISPRUDÊNCIA DA CORTE SUPREMA DE JUS- TIÇA DA COLÔMBIA SOBRE AS AGRESSÕES ENTRE EX-CASAIS: ANÁLISE DESDE OS ESTUDOS DE GÊ- NERO}

\section{RESUMO}

Este artigo analisa o tema da violência entre ex-casais e a maneira como é abordada pela jurisprudência colombiana, a partir de uma perspectiva de gênero para examinar se há discriminação de gênero nos argumentos da atual jurisprudência da Sala de Cassação Criminal da Corte Suprema de Justiça em matéria de violência intrafamiliar, quando a agressão denunciada ocorre entre ex-casais. Para realizar este estudo, primeiro descreveremos algumas causas, estereótipos e manifestações de este tipo de violência de gênero, explicaremos também os ciclos de violência entre ex-casais, as dificuldades envolvidas na quebra desse ciclo, mesmo que o relacionamento tenha terminado, e as causas e eventos da retratação. Em segundo lugar, serão identificados os argumentos da Corte oferecidos nos 
casos em que estudou esse problema e, posteriormente, serão examinados desde uma perspectiva de gênero para determinar se existem critérios suspeitos de discriminação de gênero.

Palavras-Chave: Gênero, ex-casais, jurisprudência, violência intrafamiliar.

\section{INTRODUCCIÓN}

Todos hemos conocido al "amigo de un amigo" que ha tenido una pareja con comportamientos agresivos, posesivos o violentos, que no terminan con la ruptura de la relación. Esto ocurre porque en muchas ocasiones alguna de las personas que componían la pareja se queda en la etapa de la negación del duelo; no puede ver que la situación de su vida sentimental cambió y no puede obligar a la otra a mantenerse en una sociedad económica y emocional que no quiere. Estos sentimientos se derivan de prejuicios sobre el fracaso del proyecto de vida al terminar una relación sentimental: se cree que se deja de tener valor como persona por no tener a otro ser humano al lado o que por haber tenido una relación sentimental se adquirió un derecho de propiedad sobre este. En esta sociedad en la que la propiedad privada es casi tan importante como la dignidad humana, se considera legítimo emplear cualquier tipo de armas emocionales e incluso físicas para recuperar lo que considera propio. Se escuchan en el argot popular las siguientes frases: "si no eres mía(o) no eres de nadie", "necesitas a tu media naranja", "le ha ido mal en la vida, está divorciada(o)", "pasaste al mercado de lo usado", , "eres mía(o) y yo soy tuyo(a)", "sin mí no eres nadie", "nadie te va a querer como yo", "en la guerra y en el amor todo se vale", entre otras muchas, incluyendo todas aquellas que tienen que ver con el mito del príncipe azul.

Este tipo de situaciones es muy común en nuestra sociedad. Según estadísticas de la Superintendencia de Notariado y Registro entre febrero de 2016 a febrero de 2017 se registraron en el país 64.709 matrimonios, 24.994 divorcios, 10.037 uniones maritales de hecho y 1.133 disoluciones maritales de hecho (Superintendencia de Notariado y Registro, 2017), sin contar, obviamente, con las separaciones de cuerpo y de hecho que no se registran. Pese a que son pocas las estadísticas sobre violencia contra exparejas sentimentales, no son pocos los casos: el Instituto Nacional de Medicina Legal y Ciencias Forenses (2016) registra datos estadísticos sobre los homicidios de mujeres en Colombia donde el presunto agresor es la pareja o expareja, indicando para el año 2014, 90 casos; para el año 2015, 81 casos y para el año 2016; 101 casos. Con respecto a las mujeres víctimas de violencia intrafamiliar tampoco se diferencia entre parejas y exparejas, pero se tienen para el año 2014, 31.766 casos; para el 2015, 29.027 casos y para el año 2016, 36.194 casos. En un registro más reciente, el Instituto Nacional de Medicina Legal y Ciencias Forenses (2017) reporta que de 71.980 valoraciones médico legales en el contexto de violencia de pareja para los años 2016 y 2017, el segundo agresor más 
concurrente es el excompañero, con un porcentaje del $34 \%$ de los casos, igualmente informa que de las 10.169 valoraciones de riesgo de violencia mortal contra mujeres por parte de su pareja o expareja, un $39 \%$ se encuentra en riesgo extremo y el $21 \%$ en riesgo grave.

Con esta breve información estadística se puede deducir que la violencia contra exparejas sentimentales es de trascendencia nacional y las decisiones jurídico políticas que se toman sobre este tema repercuten sobre una importante cantidad de población.

Este tipo de violencia trasciende no solo la integridad física de las personas que conformaron la pareja en sí (lesiones personales), sino también la integridad psicológica en la capacidad de socializar y de establecer las relaciones emocionales y de confianza necesarias para mantener una salud mental y, por ende, una unidad familiar tanto con la expareja, que resulta víctima, como con los hijos de esa relación, que deben ser testigos de los vejámenes entre sus padres -vejámenes que resquebrajan desde lo más profundo ese círculo de seguridad que debe representar la familia.

Un juez que conoce un asunto de violencia contra una mujer debe considerar que cuando se es víctima de maltrato por un ser amado es muy difícil tomar la decisión de separarse de su agresor, y no por el prejuicio de que las mujeres que se mantienen conviviendo con su agresor y lo perdonan, lo hacen por muchos factores culturales que les impiden terminar con la agresión, como son la discriminación por parte de la misma familia, que junto con la agresión y el arrepentimiento posterior, se vuelven un círculo vicioso que las hace creer que "todo va a mejorar", que "esta vez sí va a ser la última", que "esta vez él no tuvo la culpa, fue por mi culpa" y que hacen que se aferren a las épocas buenas de la relación como a un salvavidas. Para llegar a esta etapa de sumisión, las víctimas han tenido que pasar por golpes, maltrato psicológico y sexual; amenazas a su vida y la de sus hijos, que las hacen pensar que un comportamiento pasivo es la única forma es la única forma de convivir con la situación. Así que romper un círculo vicioso no siempre depende de la sola decisión consciente de una persona, lo que lo hace tan complicado y a la vez valeroso de lograr. Por ello, ante un caso de violencia de género como el que se expone y que continúa luego de la ruptura de la relación, estas circunstancias necesariamente deben ser consideradas por el juez para tomar cualquier decisión sobre el caso en aras de llegar a una solución en justicia material.

La preocupación que incentivó este trabajo de investigación es el desvalor que se le da judicialmente a la violencia que se genera entre exparejas sentimentales, que en su momento convivieron e incluso tuvieron hijos, pues no se consideran siquiera las razones que generan tal violencia y que no se pueden comparar al modus operandi de unas lesiones personales dolosas. 
Este artículo se concentra en determinar, desde un enfoque de género, cuáles son los criterios jurisprudenciales que permiten proteger a las víctimas de maltrato por parte de su expareja sentimental, para lo cual se identifican los criterios de violencia de género entre exparejas sentimentales, con el propósito de concientizar sobre la gravedad del problema. Luego se examinan los argumentos para la variación de la jurisprudencia de la Sala de Casación Penal de la Corte Suprema de Justicia en la interpretación de «núcleo familiar», y se concluye que sobre el tema de violencia entre exparejas no se utiliza ni se ha utilizado una perspectiva de género para su solución.

Para la realización de este artículo de investigación se utilizó una metodología de tipo dogmático jurídico con enfoque cualitativo, un análisis documental de doctrina y teoría sobre violencia entre exparejas, además de un análisis documental de tipo normativo, de jurisprudencia de la Sala de Casación Penal de la Corte Suprema de Justicia, teniendo como criterios de análisis el concepto de núcleo familiar en casos de violencia intrafamiliar y la relación entre personas separadas o divorciadas, convivientes en misma residencia o no, con hijos o no, desde una perspectiva de género siguiendo una metodología de análisis de género, de acuerdo a los pasos que expone Facio (1992), utilizando un método deductivo.

\section{GÉNERO Y VIOLENCIA DE GÉNERO, SUS REPRESEN- TACIONES Y FACTORES ENTRE EXPAREJAS}

Dado que el sistema patriarcal ha prevalecido en nuestra cultura durante siglos, se piensa que la perspectiva de género consiste en radicalizar la protección a las mujeres y desatender los derechos de los hombres, por lo que se ha llegado a ridiculizar y estigmatizar a las personas que la promueven con términos como "feminazis" y "lesbianas" y hasta apropiarles la capacidad y deseo de "homosexualizar niños". Esto, precisamente, evidencia la violencia de género de nuestra sociedad y la resistencia al cambio de la humanidad. Pese a su mala fama, el estudio de una situación jurídica desde un enfoque de género busca visibilizar un conflicto desde las relaciones sociales que se dan en su interior, no simplemente el contrato o la lesión, sino las razones humanas que lo generan; las desigualdades de poder entre las personas; las relaciones jerárquicas desde lo político, por parentesco y la distribución de trabajo, para tratar de equiparar las cargas desde el derecho y la justicia, y garantizar un verdadero acceso a la justicia a todos los seres humanos.

El "género", tiene muchas definiciones, Comesaña (2004):

"El género ha sido definido como una construcción cultural que rige las relaciones sociales entre los sexos y los códigos normativos y valores -filosóficos, políticos, religiosos-, a partir de los cuales se establecen los criterios que permiten hablar de lo masculino y lo femenino, y unas relaciones de poder asimétricas, subordinadas, aunque susceptibles de ser modificadas en el transcurso del tiempo". (p. 6) 
El enfoque de género busca, en primer lugar, concientizarnos de que a nivel social quien ha tenido la voz y el poder de redactar la historia y la ciencia, ha construido por siglos estereotipos y roles de género que instauran un trato determinado según el género de la persona. Debemos reconocer que nos encontramos inmersos en un sistema social simbólico que asigna valoraciones positivas o negativas a las personas dependiendo de su género, y con base en ello se desenvuelven los sistemas de poder, dominación $y$ control de un género a otro. Una vez se reconoce la desigualdad de género y sus fuentes, se busca deconstruirlo, desaprender y cuestionar las desigualdades derivadas de las supuestas diferencias naturales entre los sexos, para poder luego edificar un nuevo constructo social de género en la que las imposiciones y cargas a nivel social, económico, político y familiar, que no se fundamenten en "la naturaleza". Si bien debemos reconocer las diferencias, no por ello se deben imponer desigualdades.

Una de las formas en que se evidencia la violencia de género es la violencia de pareja. La intimidad de una relación sentimental es el perfecto escenario para que se infundan con mayor facilidad los prejuicios de género, las inseguridades y la repetición de estándares aprendidos en la niñez acerca de cómo se debe demostrar y recibir amor, lo que genera que se presente violencia y que la misma sea tolerada.

La violencia infligida por la pareja, para la Organización Mundial de la Salud (2013) se diferencia de la violencia doméstica o intrafamiliar y violencia contra la mujer, pues la doméstica o intrafamiliar abarca el maltrato que se le ocasiona a los niños, ancianos y cualquier otro integrante de la familia. La violencia contra la mujer no abarca la violencia que se suscita contra la pareja, ni implica que se presente la violencia por su pareja. La OMS caracteriza esta modalidad de violencia de género así:

"se presenta en todos los entornos y grupos socioeconómicos, religiosos y culturales. La abrumadora carga mundial de violencia infligida por la pareja es sobrellevada por las mujeres. Si bien las mujeres pueden ser violentas en sus relaciones con los hombres, a menudo en defensa propia, y a veces hay violencia entre parejas del mismo sexo, los agresores más comunes en la violencia contra la mujer son compañeros (o excompañeros) íntimos de sexo masculino. En cambio, es mucho más probable que los hombres sean víctimas de actos de violencia perpetrados por desconocidos o por conocidos que por alguien más cercano a ellos”. (p. 1)

Para Marchiori (2010) el ciclo de la violencia conyugal o de pareja se presenta en 3 estadios: primero, la acumulación de tensiones en la relación y comunicación de la pareja; luego, la eclosión aguda de violencia por parte del golpeador; para llegar a la luna de miel o amor arrepentido, en donde inmediatamente se reinicia el ciclo de los golpes y maltrato emocional en lapsos de tiempo cada vez mas cortos. Es así que la mujer golpeada -generalmente víctima de este tipo de conductas, pues para el 2013 el 
$77,58 \%$ de la violencia intrafamiliar se dio contra mujeres y un $22,42 \%$ contra hombres (Contretas, 2014)-, tiene uno de dos caminos: luchar o reprimirse. Cuando opta por el primer camino, puede que el agresor modifique la forma en que intenta dominar a la mujer o puede que responda constantemente de forma más violenta, lo que generalmente obliga a la víctima a convencerse de que se encuentra en total indefensión y piense que si se defiende, pone en peligro su vida o la de sus seres queridos. Producto de la violencia estructurada de la que es víctima desde niña, renuncia a tratar de defenderse o a buscar formas de alejarse. Puede hasta convencerse de que en verdad fue por su culpa, que hizo algo para merecer el maltrato (Rodríguez, 2015) y le resta importancia a las lesiones, lo que la lleva a optar por el camino de reprimirse, aprenden a vivir asustadas por la vida de su familia y de sí misma, y así trata de "no molestar" a su pareja sentimental, de no hacer algo que pueda reactivar su agresión como reclamar, no defenderse y aceptar las disculpas o pedirlas. Esa situación de debilidad, frustación, miedo, culpa, vergüenza y negación hace que cuando llegue a la etapa de amor arrepentido quiera creer en el cambio de su pareja y ceda, recordando quizás, la época de inicio de la relación en la que seguramente no eran tan evidentes las agresiones a su autonomía y dignidad, pues ambos se encontraban bajo el manto del enamoramiento.

La OMS (2013) sostiene que las mujeres no son víctimas pasivas, sino que podrían decidir no abandonar a su pareja violenta como una estrategia para protegerse a sí mismas y a sus hijos, o también como respuesta al temor a las represalias, por falta de apoyo económico de parte de familiares y amigos, o también por la estigmatización o posible pérdida de la custodia de los hijos asociada con el divorcio, además de por amor y esperanza de que su pareja cambie.

El ciclo de violencia de pareja afecta la autoestima, la dignidad e incluso la capacidad de autoprotección de la víctima (la más instintiva en el ser humano). Por esto es que generalmente, cuando toma la decisión de pedir ayuda o salir de la casa que comparte con su victimario, se debe a "los gravísimos golpes sufridos y por el riesgo de violencia y vulnerabilidad de todos los miembros de la familia, en especial de los niños" (Marchiori, 2010 , p. 210). Es decir, luego de haber padecido distintos tipos de violencia, de aceptar hacer cosas sin su voluntad, de ser torturada y violada quizá por años; luego de estar traumatizada, cuando ve inminente su muerte o la de un ser querido, es que decide irse y romper el vínculo de su matrimonio o unión marital de hecho.

Pero lamentablemente, la sola separación o rompimiento de la pareja no destruye el ciclo de violencia de pareja. Ágreda y López (2017) señalan que de no elaborar un proceso de separación, el duelo por el divorcio psicológico y sus etapas -así como de no tomar un tiempo para adecuarse al nuevo estado, siendo necesario en todo caso que tengan recursos fami- 
liares, religiosos o sociales de apoyo en lo emocional y económico para que se dé una adaptación-, se puede generar nuevamente violencia, dependiendo de la interrelación de la pareja, continuando con las agresiones que se vivieron cuando existía la relación o creando nuevas.

Para Ágreda y López (2017) la denuncia o el inicio de un proceso judicial disminuyen la violencia haciendo que se limite a la verbal o psicológica, persistiendo cuando el agresor intenta socavar la voluntad de la víctima, amenazándola para el retiro de la denuncia. Resultando, en muchos casos, en una retractación, acto que según Torres (2013) es propio de una víctima que, pese a la separación del victimario, sigue siendo manipulada. El victimario retoma el ciclo de violencia "portándose bien" y simula un cambio. La víctima se retracta pensando que todo está solucionado y que tiene el control de la situación, pese a que después, por volver a caer en el ciclo de violencia, la situación realmente no ha cambiado. Otras razones de retractación vienen del miedo a la expareja, o del sentimiento de culpa de hacer pasar al padre por un proceso penal y exponerlo a una condena de orden económico y social (Rodríguez, 2015); igualmente, las obligaciones maternales y el rechazo a una sanción penal, entre otras, que también tienen un componente fuerte de violencia de género y estereotipos, obligan a la madre a no buscar justicia por los delitos que contra ella se cometen. Así, por el bienestar de sus hijos y de la composición de su familia, la cual ella debe cuidar y responsabilizarse por mantenerla unida. La retractación también es motivo para que las personas que trabajan en el sistema judicial (desde los policías y fiscales hasta jueces y magistrados) que no están capacitados para entender la gravedad cíclica y psíquica de ser víctima de violencia de pareja, se dejen llevar por los estereotipos de género y menosprecien los casos, implicando con esto una revictimización.

Igualmente, Ágreda y López (2017) precisan que suelen permanecer los lazos emocionales aunque ya no tengan una naturaleza amorosa, y de ahí es que se generan los conflictos después de la separación. Esto es evidente en una relación en la que existen hijos en común, pues se mantienen los lazos emocionales por estos, y eso hace que los procesos de divorcio -o separación de las uniones maritales de hecho, liquidaciones de la sociedad conyugal o patrimonial, custodia, alimentos, patria potestad y visitas- sean tan conflictivos y nocivos (pues no se ha generado un adecuado proceso de duelo y se tienen problemas de raíz como dificultades económicas, celos y dependencia de sustancias psicoactivas o alcohol). Esto afecta no solo a la expareja víctima de maltrato sino que también a los hijos (psicológica y socialmente), quienes aunque no reciban el golpe, insulto o violencia económica, tienen que estar continuamente expuestos a esa tensión familiar, lo cual es un indicador de repetición de pautas intergeneracionales en relación a la violencia de pareja. Gómez, Martín y Ortega (2017) concluyeron que existe un perjuicio mayor en el desarrollo psicosocial del niño que es testigo de los conflictos o violencia de pareja, 
que el que pareciera generar con el divorcio de sus padres en sí mismo y el cambio de la estructura familiar, reflejando también que resultan más afectadas con síntomas de ansiedad las niñas que los niños.

Facio (2002) permite evidenciar la importancia y trascendencia de estudiar las circunstancias sociales, familiares y judiciales en los casos de violencia intrafamiliar. Con respecto a los hijos en común, tomando posición desde un enfoque de género, ha dicho:

“¿Qué pasa por la cabeza de niños y adolescentes que ven a sus padres humillar y golpear impunemente a sus madres durante toda su estancia en la familia? ¿Creen que un niño que varias veces durante su niñez ha visto a su padre enviar a su madre al hospital con la nariz quebrada y las costillas rotas, pueda tener respeto por "la familia", "la verdad", "la justicia", etc.? Más cuando ve que a ese padre la gente lo respeta por su honestidad, su inteligencia o lo que sea.

Todavía hay gente que cree que la violencia intrafamiliar contra las mujeres sólo afecta a las mujeres y que nada tiene que ver con la descomposición social y la falta de fe en los valores éticos y en los derechos humanos, o con la falta de credibilidad en las instituciones políticas y sociales. Pero esto ocurre debido a que la mayoría de los análisis de la realidad se hacen sin perspectiva de género. ¿Por qué? Porque es lógico pensar que si una persona se explica el mundo desde un punto de vista androcéntrico o hasta gynocéntrico, no va a ver la realidad y por tanto no va a ver las conexiones que hay entre todas las cosas". (p. 93)

Son pocas las investigaciones sobre el tema de la violencia o maltrato propiciado por la expareja. La mayoría se limita a la violencia contra la pareja o tratan los dos temas indistintamente. Rescato la labor de Zaldívar, Gurrola, Balcázar, Moysén y Esquivel (2015) quienes afirman que la violencia postseparación se debe entender como:

"cualquier forma de abuso (sexual, psicológico, moral o físico), ejercido por un exesposo, examante u otra expareja (Brownridge, 2006). Una investigación reciente indica, una fuerte relación entre el divorcio y la victimización después de la separación (Bo-Vatnar y Bjorkly, 2011). Estos hallazgos han permitido entender, desde una perspectiva interaccional, la violencia postseparación como un fenómeno complejo, heterogéneo y dinámico". (pag. 2)

En estos casos es importante contextualizar bajo la perspectiva de género, pues el fenómeno de la violencia contra la mujer se debe al contexto cultural de patriarcado en donde el hombre desea el control y así, ante el divorcio o separación, advierte la amenaza real de perder su poder, por lo que intenta preservarlo por diversos medios. Aún si en la relación no se había presentado violencia, puede que en la etapa posterior a la relación se utilice violencia física o psicológica mediante acecho, o violencia 
sexual, patrimonial, o control económico (con sus obligaciones alimentarias, la liquidación de sociedades), o también mediante la utilización de sus hijos para afectar a su pareja psicológicamente, con amenazas a ella y a sus hijos, seguimiento, o alienación parental. Para Zaldívar et al. (2015) cuando la pareja tiene hijos en común, se crea un campo fértil para continuar el maltrato derivado del continuo trato que debe tener por ocasiones de las obligaciones parentales.

Pese a estos comportamientos agresivos e insensatos de los victimarios, la violencia contra la pareja, en la mayoría de los casos no se trata de un síntoma de una enfermedad psicológica del agresor. Espinar (2003) afirma que aunque no hay acuerdo definitivo al respecto, sí "está ampliamente extendida la idea de que entre los maltratadores no hay una presencia mucho mayor de trastornos psicopatológicos en comparación con la existente en el conjunto de la población" (p. 98-99). Se suele coincidir en los siguientes rasgos de personalidad de los victimarios: "ansiedad, poca capacidad empática, hostilidad, falta de control de la ira, impulsividad, actitud posesiva, niveles bajos de autoestima, celos, déficit de habilidades sociales y comunicacionales, etc." (p. 99).

Existen estudios en los que se identifican los patrones de toma de decisiones o el equilibrio de poderes como factores para calificar las relaciones de pareja violentas, así como también factores individuales, como transmisión generacional de la violencia, la dependencia de sustancias psicoactivas o alcohol, o circunstancias de frustración y situaciones de estrés, como las de carácter económico o laboral.

Por eso es que, sin lugar a dudas, se deben concluir los siguientes tres puntos.

1. Desde un enfoque de género, en nuestro sistema social, las mujeres son discriminadas. El hecho de tener hijos impone culturalmente la responsabilidad de luchar por otro ser humano; responsabilidad que indudablemente también le corresponde al padre, pero socioculturalmente no se le impone, pues el estereotipo machista de la madre protectora, hace que los hombres infectados por este estereotipo se desentiendan de su papel que es igual de biológico y natural que el de protección de la madre, dejando a esta la tarea que creen erróneamente que les corresponde: protección y crianza de su descendencia 24/7, carga que ni los padres machistas ni las mujeres no madres tienen. La mujer no madre frente a la mujer madre, se diferencian en este sistema social plagado de violencia de género, lo cual se deben reconocer, para luego cuestionar, deconstruir y modificar.

Si bien es cierto las mujeres no madres también son víctimas de violencia de pareja, una vez se rompe la relación, hay menos probabilidades de que se continúe, en contraste con el caso de las madres, pues la carga sociocultural que se les impone es diferente. El hecho de mantener contacto con el maltratador por sus hijos en común es un escenario propicio para continuar el 
maltrato, utilizando precisamente ese lazo inquebrantable para dominar nuevamente a la mujer o intentar hacerlo; amenazarla con que no le dará la cuota alimentaria, y así no podrá "salir adelante" con sus hijos, o se lo quitarán o los dañarán de alguna manera (, 2015). Esto sin tener en cuenta que las mujeres no madres tienen mayores posibilidades de continuar con su preparación académica y profesional, de tener mejores empleos y salarios; unas posibilidades que, por el mismo machismo y violencia estructurada a la madre, aunque no imposible, sí es mucho más demandante, más aún para la madre soltera, pues el papel de única cuidadora de sus hijos le resta tiempo de dedicación que en un mundo capitalista y de constante competencia por becas, por puestos de trabajo y salarios, le hace más difícil su crecimiento laboral, profesional y empoderamiento. Esas diferencias socioculturales machistas que afrontan las madres, hacen que se les dificulte aún más romper la relación marital y separarse de su compañero maltratador, pues tienen mayores sentimientos de miedo, culpa y vergüenza, y mayor carga emocional (Rodríguez, 2015), cultural y social derivada de los estereotipos de género que les dice que se queden en la relación, pues el machismo utiliza a sus hijos como el grillete de su vida, cuando no tiene por qué ser así; pues no hay razón por la que ella sea la única que cuide y se responsabilice de un ser humano que ella no creó sola.

Por ello, cuando finalmente logran la separación, aunque hayan realizado un acto de valentía y de fuerza, se encuentran vulnerables, amenazadas y bajo una situación desesperada que al principio les parece incontrolable e insoportable. Recordemos que para el ser humano todo cambio al principio es difícil, pero este le genera a la mujer madre una incertidumbre no solo de su vida, sino de la de sus hijos, lo que la hace susceptible, sin un acompañamiento psicoterapéutico que le permita aprender de lo sucedido, superarlo y empoderarse, de volver a ser víctimas de maltrato por su ex pareja, volviendo a vivir el mismo infierno, pero sin que se limite a su hogar.

2. Pese a que Torres (2013) concluye que debería dársele más participación a la víctima para la resolución de su caso en el área penal y administrativa, debido a sus propias necesidades, refiriéndose a lo que pudiéramos denominar un tipo de justicia restaurativa en procesos de violencia intrafamiliar, no puede formularse esa opción sin requisitos o reparos. Aunque se trata de una forma de acercar a víctima y victimario, su familia o comunidad, y recomponer sus relaciones o tejido social, lo que sería ideal para verdaderamente resolver el conflicto, dado el ciclo de violencia que se presenta en estos casos, no concuerdo en que a toda víctima sin ninguna contemplación adicional, se le dé el poder de determinar qué hacer con su victimario y considerar sí merece un castigo y cuál sería. Lo que sí consideraría viable, si la víctima (previo a esa decisión), tuviera una atención psicoterapéutica y capacitación en alguna técnica u oficio, que le permitiera salir del ciclo de abuso y también empoderarse como persona para poder cambiar su vida, pues solo de esta manera verdaderamente 
tendrá la capacidad y autonomía suficiente de decidir, y así podrá buscar lo mejor para ella y su familia, sin que la motive el miedo a su expareja. Claro que de intentarse este tipo de justicia restaurativa del conflicto familiar, paralelamente se debería trabajar de forma psicosocial con el victimario y el entorno familiar que comparten.

3. Cuando se maltrata a la mamá de un niño, niña o adolescente, no solo se afecta a la mujer que recibe los insultos, golpes y abusos. No es una agresión individual que lesione solamente su integridad física y personal, sino que afecta toda la vida de su hijo en común, y lo que él o ella entienden por familia. De ahí también podemos deducir que es un estereotipo de género el concepto de que la sola separación de padre y madre puede afectar a los niños. Muchas madres soportan los maltratos de su pareja, el padre de sus hijos, porque están convencidas que si rompen la relación, sus hijos sufrirán, pues se quedarán sin un proveedor, ejemplo, figura masculina y paterna y eso afectará su desarrollo emocional y social. Todo por ser hijos de padres separados o divorciados; sin embargo, esto es un concepto impuesto por el mismo patriarcado, que inclusive ahora, aún con la liberación femenina, hace que muchas mujeres acepten el papel impuesto de madre abnegada, sufrida, maltratada y abusada, como un sinónimo de buena madre. Sin embargo, según la investigación de Gómez et al. (2017), es un mayor perjuicio psicológico el que recae en el niño que sea testigo sin voz ni voto de la violencia entre sus padres. Entonces, se trata de un concepto más que busca que la madre no se defienda, que trata de manipularla para que mantenga el status quo del hombre machista que necesita tener a su compañera como una posesión, dominarla para que le dé el estatus de un hombre de familia que tanto aprecia la sociedad, pero que le genera un desvalor laboral y económico a la mujer.

\section{3. ¿LAS EXPAREJAS CONFORMAN UN NÚCLEO FAMILIAR SEGÚN LA JURISPRUDENCIA COLOMBIANA?}

La jurisprudencia de la Corte Suprema de Justicia, Sala de Casación Penal, desde la expedición de la Ley 294 de 1996 ha generado diferentes posiciones con respecto al problema jurídico de si la conducta de maltrato a una expareja debe ser calificada jurídicamente como violencia intrafamiliar.

La providencia fundadora de este problema jurídico es el Auto del 22 de enero de 1998 (Exp. N559, 1998), por el cual la Corte contestó a este problema con un “NO", porque consideró que, de acuerdo a los fines de protección del artículo $2^{\circ}$ de la Ley 294 de 1996, la definición de núcleo familiar no incluye a los excompañeros permanentes, ni siquiera en el evento de tener hijos en común, porque el literal b)3 del citado artículo hace relación al vínculo de filiación exclusivamente.

3 "b) El padre y la madre de familia, aunque no convivan en un mismo hogar". 
No obstante, la posición varió con el auto de Sala Plena de la Corte Suprema de Justicia del 23 de marzo de 2006 (Exp. 2005-00032, 2006), con la que se respondió al problema jurídico planteado, que el maltrato a un expareja sentimental SI debe calificarse como violencia intrafamiliar, si la pareja tiene hijos en común, por cuanto: (i) la Ley 294 de 1996, busca proteger a la institución familiar y no un tipo determinado de familia. Así que subsiste la familia cuando, mediando hijos, el padre o la madre, abandonan la casa paterna o materna, dejando a sus hijos con el otro progenitor. Fundamenta esta posición en lo dicho por la Corte Constitucional en sentencia T-523/1992, en la que explica que la obligación de los padres es procurarle a sus hijos un ambiente familiar adecuado, aún después de la ruptura de la pareja. Con ello concluye que con la no convivencia de la pareja, no se excluye necesariamente la unidad esencial e irreductible que protege la Constitución. Y (ii) para reforzar su posición, trae como argumento de autoridad legislativa las consideraciones que se tuvieron en cuenta por el legislador para la expedición de la Ley 294 de 1996, para afirmar que el legislador buscaba reprimir conductas ilícitas al "interior de la relación familiar o como consecuencia de haber existido una relación familiar". Con lo que deduce que la Ley 294 de 1996 al momento de definir quiénes hacen parte del núcleo familiar, dice "padre y la madre de familia", por lo que es suficiente que los sujetos tengan esa calidad respecto de un hijo(a), sin que importe si mantienen un matrimonio o unión marital de hecho ni si conviven. Protección que se da en razón a los derechos del niño, niña o adolescente a tener una familia y no ser separada de ella.

Tesis que la Sala Plena de la Corte Suprema de Justicia reiteró en Auto del 28 de agosto de 2008 (Exp. 2008-0033, 2008), en el caso de una mujer en estado de embarazo se encontró con su expareja, quien la agredió físicamente cuando ella le reclamó por la cuota mensual para su alimentación, pues esperaba un hijo suyo, con lo cual le causó 5 días de incapacidad médica legal sin secuelas. En esta oportunidad, la Sala Plena refirió los argumentos emitidos en el Auto de sala plena del 23 de marzo de 2006 para afirmar que la unidad familiar, cuando existen hijos, se mantiene entre el padre y la madre, aún después de la ruptura de la relación, porque eso era lo que buscaban proteger los legisladores de la Ley 294/1996 y porque ha sido esa la postura de la Corte Constitucional desde la sentencia T-523/1992.

Posterior a esto, la Corte no había vuelto a discutir este problema jurídico, hasta el 7 de junio de 2017 (Rad. 48047, 2017), cuando se le presentó el caso de una expareja con hijos que convivían bajo el mismo techo, en el que el hombre agredió a su expareja delante de ellos de forma verbal y físicamente, generando una incapacidad médica legal definitiva de 8 días. Con este caso, se volvió a cambiar la tesis, a un "NO" rotundo porque consideró que cuando el artículo 2 de la Ley 294 de 1996 y el artículo 26 de la Ley 1257 de 2008 consagran que se integra un núcleo familiar con "los cónyuges o compañeros permanentes", pretende proteger de las agresiones que 
uno le cause al otro, solo si mantienen un núcleo familiar (convivencia); y cuando señala que un núcleo familiar se compone con "el padre y la madre de familia, aunque no convivan en un mismo hogar", protege de las lesiones que se produzcan no entre los padres, sino teniendo al hijo como posible autor o victimario. Concluye la Corte que los padres "son familia respecto de sus hijos $y$ por siempre, pero si esos progenitores no conviven en el mismo hogar no conforman entre ellos un núcleo familiar". Es decir, cuando la convivencia termina, las parejas pierden la protección legal que el derecho les da sobre el delito de violencia intrafamiliar y acoge las lesiones como personales dolosas.

Los argumentos que sostienen las anteriores conclusiones son: (i) para la Corte, el punible de violencia intrafamiliar no busca la protección de cualquier miembro de la familia, sino que la víctima y el victimario tienen que hacer parte del mismo contexto nuclear, pues no se protege a la familia en abstracto, como institución básica de la sociedad, sino "la coexistencia pacífica de un proyecto colectivo que supone el respeto por la autonomía ética de sus integrantes". (ii) Si bien la Constitución permite que nazca una familia por voluntad de las personas, es dable concluir que también puede terminarse por su voluntad, ello respecto de las parejas, pero no ocurre lo mismo con la relación paterno filial, porque siempre serán padres e hijos. (iii) No puede constituirse la noción de "núcleo familiar" desde el derecho de los niños a tener una familia y no ser separado de ella, porque se impediría el divorcio o separación, quebrantando la dignidad, autonomía personal y autodeterminación de los progenitores, desconociendo que en ocasiones disfuncionales es más garantía de los derechos de los niños la separación de uno de sus padres para lograr tranquilidad en su contexto familiar nuclear. (iv) La protección estatal de la familia no se consigue solo con el derecho penal. Afirmar que cuando termina la convivencia de pareja, o sin siquiera haber convivido, se mantiene entre ellos el núcleo familiar, cuando tienen hijos comunes menores de edad, corresponde a una ficción ajena al Derecho Penal. (v) En un caso anterior (Rad.35764), la Corte, ante una denuncia entre hermanos, consideró que no había afectación al núcleo familiar, porque cada uno de los sujetos tenían su propio núcleo familiar o unidad doméstica separada, similares argumentos se utilizó en el caso (Rad.34510) en el que se estudió la circunstancia de agravación de un homicidio, así como en el caso de violencia intrafamiliar con compañeros permanentes que no habían cumplido los 2 años de convivencia (Rad.33772) y respecto de las parejas homosexuales en la sentencia C-029/09. (vi) La modificación al artículo 229 del CP, con el artículo 33 de la Ley 1142 de 2007, "reitera la necesidad de que agresor y agredido pertenezcan a una unidad doméstica, inclusive, sin que medien vínculos de consanguinidad, pues no se trata de asegurar la tranquilidad y armonía de la familia in extenso, sino del hogar en concreto". (vii) Desde el derecho comparado, se aporta posiciones del Tribunal Supremo Español, en el cual el punible similar al de violencia intrafamiliar se le llama "violencia doméstica" y el Código Penal Federal de México, con el que se consagra para 
su configuración que tanto víctima como victimario deben convivir.

Esta tesis de considerar que el maltrato a la expareja no conviviente, no permite que se configure el tipo penal de violencia intrafamiliar, se ha mantenido hasta el momento. Reiterándose en sentencia del 6 de diciembre de 2017 (Rad.50775, 2017) en la que se estudiaron las agresiones verbales y físicas de parte de un hombre a su exesposa, de quien se había divorciado hacía 3 meses y con quien tenía 2 hijos menores de edad. En este caso, pese a que el fallo de segunda instancia se profirió antes del cambio de posición jurisprudencial, y con fundamento en una visión amplia del núcleo familiar, derivada de la sentencia de la misma Sala del 3 de diciembre de 2014 (Rad.41315), se casó la sentencia por encontrarse que los implicados pese a tener unos hijos, no convivían juntos, por lo que se cambió la calificación jurídica de la conducta a lesiones personales dolosas.

Con similares argumentos, en sentencia del 6 de diciembre de 2017 (Rad. $49956,2017)$, la Corte casó la sentencia de segunda instancia, para modificar la calificación jurídica a lesiones personales dolosas en el caso de una mujer que cuando se encontró con su exesposo y padre de su menor hijo, este la amenazó de muerte por algo que supuestamente dijo de él y le propinó golpes, causándole 8 días de incapacidad médica legal definitiva sin secuelas. Esto por considerar que el núcleo familiar que protege el tipo penal de violencia intrafamiliar, debe ser actual y vigente, debe asegurarse la existencia material y real, no formal, de una familia y por ello no pueden componerla quienes no conviven.

Igualmente se reiteró la tesis negativa, que califica el maltrato a una expareja como lesiones personales dolosas, en auto del 17 de enero de 2018 (Rad. 50274, 2018), en el que una mujer, al recoger a su hijo menor de edad de la casa de sus abuelos paternos, recibió maltrato verbal y un cabezazo que le produjo una incapacidad médica legal definitiva de 10 días de su excompañero sentimental y padre de su hijo. Como en el auto del 4 de abril de 2018 (Rad. 51956, 2018), en el que se analizó el caso de una ex pareja, aún conviviente, porque el hombre agredió en el rostro y brazos a su excompañera permanente delante de su hijo común, ocasionándole una incapacidad médica legal definitiva de 5 días sin secuelas, en este asunto se calificó la conducta como violencia intrafamiliar, resaltándose que esto era así no porque tuvieran un hijo en común, sino porque el maltrato se dio entre convivientes, quienes conforman una unidad doméstica.

La sentencia más reciente -hasta el momento- en la que se plantea este problema jurídico, es la emitida el 4 de abril de 2018 (Rad. 46784, 2018), en la que se planteó el caso de una mujer que cuando decidió terminar la relación de pareja con el padre de su hija y con el que convivía para el momento de los hechos, fue retenida de manera violencia por su excompañero permanente, quien la hizo subirse a diferentes medios de trans- 
porte en horas de la noche y madrugada, y la sometía para besarla y para firmar un recibo de constancia de pago de cuota alimentaria a favor de su hija común, ocasionándole una incapacidad médico legal de 6 días. El problema jurídico principal en este caso era el establecer si procedía de la modificación de la calificación jurídica de la conducta por la que el imputado se allanó a los cargos. Se dijo que de considerarse que existían vulneraciones a garantías fundamentales procedería, mediante la nulidad del acto de allanamiento. Pero, la Corte consideró que en este caso no se justificaba decretar la nulidad, porque como se originaron los hechos al momento en el que la víctima le comunicó la decisión de terminar la relación al victimario y para ese entonces convivían como pareja, por lo que se cumpliría los criterios establecidos en la sentencia del 7 de junio de 2017 (Rad. 48047) para calificar la conducta como violencia intrafamiliar y no "lesiones" como lo dijo el Tribunal de segunda instancia.

\section{CONCLUSIONES}

De la línea jurisprudencial podemos deducir que en el 2006 y 2008 la Sala Plena del Alto Tribunal sostuvo la tesis de que los maltratos entre exparejas sí configuraban una violencia intrafamiliar. Aunque la tesis es positiva a nuestro problema jurídico, en sus argumentos no se refleja una perspectiva de género. Por el contrario, el amparo que se les da a las víctimas de maltrato por la expareja se circunscribe al derecho de sus hijos de no ser separados de su familia y a la obligación que como padres tienen de mantener unas relaciones cordiales para el bienestar psicológico de sus descendientes. No se discute aquí que esa sea la obligación de todo padre: no perturbar las emociones de sus hijos, ni utilizarlos como premio u objeto de amenaza contra su expareja, pero los argumentos de esta tesis no atacan al panorama completo, ni su causa, pues el maltrato a la expareja no lo genera -en la mayoría de los casos-, la existencia de hijos en común sino las desigualdades de las relaciones de poder entre los padres, los estereotipos de machismo y sexismo, que persisten si se ve el problema social y familiar desde el lente androcentrista, que invisibiliza a las mujeres no madres y discriminan a las madres, por tan solo ser valoradas por su función con sus hijos y no como mujeres, como personas.

Lo curioso de este argumento de 2006 que pretende proteger a los niños, niñas y adolescentes a su derecho de tener una familia y no ser separada de ella, es que, pese a que perduró hasta el 2017, las denuncias por hechos de maltrato a la expareja que se presentaban por el ente acusador, no se hacían centradas en la afectación del maltrato a los hijos de esa expareja, pues se calificaban como víctimas a las madres que recibían el maltrato directamente y no el indirecto que pudiera haber afectado a sus hijos. Contradiciendo en la práctica el argumento de la jurisprudencia, pues si se aplicaba la violencia intrafamiliar para exparejas por la afectación de esta conducta para sus hijos, bajo esa premisa, sus hijos en común han debido ser las víctimas 
del punible. Lo que confirma el criterio sospechoso de violencia de género, por omitir en la jurisprudencia la relevancia del maltrato a la mujer.

Por otra parte, desde 7 de junio de 2017 contamos con una jurisprudencia vigente, reiterada y consolidada del órgano de cierre en la justicia penal, limitadora del núcleo familiar, para la interpretación del tipo de violencia intrafamiliar. Con esta tesis se considera que solo existe antijuridicidad al bien jurídico de la unidad familiar, si hay una afectación o maltrato a las personas que viven bajo la misma unidad doméstica, entendida como "bajo el mismo techo", porque se asume que el legislador con la implementación del tipo de violencia intrafamiliar, no buscó un amparo abstracto sobre la familia como núcleo de la sociedad, sino uno concreto, proteger a las personas que constantemente se relacionan, comparten convivencia diaria, y por eso son más vulnerables entre sí. Excluyendo del punible a los actos de maltrato que se generan a la expareja con la que no mantienen convivencia, sin importar si se tienen hijos comunes o no. Porque el literal b) del artículo 2 de la Ley 294 de 1996, que contempla una forma de composición de un núcleo familiar, deja de interpretarse en referencia a la conducta de violencia intrafamiliar, como el maltrato del padre o madre entre sí, aunque no convivan, y pasa a entenderse que el victimario no se relaciona taxativamente en el numeral, sino de forma tácita por corresponder al hijo en relación con los padres, quienes pueden no convivir con su hijo, pero sí configurar violencia intrafamiliar si este les propina un maltrato; último argumento que también fue el que formuló el Alto Tribunal con la sentencia fundante en 1998.

El punto positivo para esta posición, es que ya no diferencia a la mujer no madre de la mujer madre, y tampoco una vulneración a ella, pues la asume como una afectación a la familia, pero en todo caso, termina teniendo más puntos negativos, pues convierte una protección disminuida o parcializada en una desprotección total, y -lo peor- sin argumentos contundentes.

La idea principal de la tesis de la Corte Suprema de Justicia desde el 7 de junio de 2017, es que no todo asunto del derecho de familia puede ser tratado por el Derecho Penal. Hay un claro mensaje de despenalización de asuntos que otrora se conocían como violencia intrafamiliar, para disminuir su punibilidad, quizá amparada por las propuestas legislativas del momento que buscan despenalizar totalmente los delitos de violencia intrafamiliar e inasistencia alimentaria. Si bien es cierto en el Derecho Penal se tiene como principio que el uso de este sistema adversarial, sancionatorio y privativo de la libertad, sea de ultima ratio, y los conflictos familiares que trascienden a delitos no se solucionan con un proceso penal, con una pena, ni con un incidente de reparación integral, porque el sistema judicial contribuye incluso a ampliar las brechas entre víctima, victimario y su familia y así a que se mantenga el daño que con la conducta se ocasionó (la desintegración familiar), esto es así porque al derecho 
penal solo le importa el delito, y la pena que se le debe imponer por esa trasgresión a los bienes jurídicos a los que el derecho les ha dado una preponderancia, pero no la recomposición del tejido social destruido; así que con base en esto, el considerar bajo este sentido "una ficción ajena al Derecho Penal” el que las exparejas por el hecho de tener hijos comunes mantengan el mismo núcleo familiar, pudiendo el derecho resolver estos asuntos por otros medios, disminuye o silencia la problemática y la convierte en unas lesiones personales, que no tiene ni la misma pena para el infractor, ni la misma protección del Estado para la víctima y su familia, y no da una solución real al conflicto sino, por el contrario, en ocasiones agrava las desigualdades de género. Ello se asegura porque no atiende a las implicaciones que tiene la violencia de género que nació por la relación familiar preexistente (con o sin hijos) y trascendió a la separación física, sin que se haya perdido el hilo de causalidad, y se olvida de todos los estereotipos y la estigmatización de las desigualdades de poderes en el curso de una relación de pareja y posterior a su terminación, pues al agresor poco le importa si la relación terminó en la vida real, porque a él, desde la niñez le han implantado que cuando una mujer dice "no" es "sí" y que para ser un varón, ninguna mujer lo puede dejar, y debe conservar su harén, o utilizando el término sexista popular: "su ganado".

En definitiva, esta posición de la Sala de Casación Penal de la Corte Suprema de Justicia desde la sentencia del 7 de junio de 2017, no fue tomada con una perspectiva de género, ya que en sus argumentos no se plantearon las causas que generan el maltrato a la expareja ni las consecuencias que representaría este cambio de interpretación de la conducta punible, que se aplicó incluso de manera retroactiva, para las mujeres madres que son víctimas de este suplicio aún después de terminar su relación. Lo cual, según Facio (1992), en un caso como el que se presenta en este artículo, en que se evidencien conflictos derivados de las desiguales relaciones de poder entre las partes, y que deliberadamente no se valoraron al momento de tomar la decisión por el juzgador, amplifican esta discriminación y la violencia de género para las víctimas, ya no solo propiciada por su expareja sino también por la justicia a la cual acudió para que la socorriera.

Si se analiza a quién beneficia y a quién perjudica esta posición jurisprudencial, se puede afirmar desde una perspectiva de género que la desidia del Alto Tribunal de valorar la situación real, para simplificarla o generalizarla, en los casos en que siendo afectadas con el flagelo de la violencia intrafamiliar, pese a que logran separarse físicamente de su relación abusiva, han tenido que seguir en contacto con el agresor aunque no compartan techo, porque, por ejemplo, tienen hijos comunes, o son vecinos, o compañeros de trabajo. Si el agresor decide no aceptar la pérdida, no hacer el duelo correspondiente y mantener o intensificar las agresiones a su ahora expareja, esa conducta y su interpretación actual benefician al victimario, ya que en el evento de generarle a la víctima 8 días de in- 
capacidad médico legal4, en vez de representarle al agresor una posible pena mínima de 6 a 14 años5, pasa a una pena de 16 a 36 meses de prisión6, enviando un mensaje que está lejos de la función de la pena en el sistema penal de prevención general, lo que permite también evidenciar un tipo de castigo a las mujeres en el momento en que se encuentran más vulnerables, de alguna manera reprochándole que se haya revelado y haya decidido separarse físicamente de su expareja abusiva, pues la deja susceptible y vulnerable a la manipulación del victimario, beneficiándolo nuevamente en su empresa de conservación del poder sobre otra persona.

Esto se explica porque al silenciar las voces de auxilio y plantear objetivamente y a raja tabla el precepto que desde que se dé una separación física, se pierde la afectación al bien jurídico tutelado de la unidad familiar y por ende, su relevancia para el Derecho Penal, no solo se afecta la sanción punitiva de la conducta sino que también trunca las posibilidades de restauración de la dignidad y el proceso de empoderamiento de la mujer víctima, pues al entender la conducta como "lesiones personales", se le quita el acompañamiento psicosocial y asistencial en el margen de las medidas de protección7 en casos de violencia intrafamiliar, y al permitir que la conducta sea querellable -por ende conciliable y desistible-, se retrocede en la evolución del ordenamiento jurídico, ya que permite que las mujeres víctimas de este tipo de situación pueden recaer en el ciclo de violencia. Así mismo, permite que se encuentren en peligro de mayores agresiones al requerir de conciliaciones prejudiciales para el inicio de la acción penal sin el tratamiento psicosocial adecuado, consintiendo el fenómeno de retractación, el cual no siempre se da por cambio real del victimario sino por amenazas, intimidaciones o manipulaciones; expresiones que se anticipan al reinicio del ciclo que tan difícil fue para ellas salir. No se trata de que las mujeres víctimas se vuelvan unas incapaces, sino que el ciclo de violencia de pareja les puede implicar un vicio en su consentimiento y voluntad, que termina, no con la ruptura de la relación sentimental, sino con un trabajo psicoterapéutico y de empoderamiento, después del cual no permitirán que se les manipule ni amenace.

Si bien es cierto que existe violencia de género cuando se asume a la mujer como sinónimo de familia, y lo que se discute en este artículo es que se haya excluido a las exparejas del núcleo familiar, no se pretende identificar a la mujer como familia, sino exponer que este cambio jurisprudencial

4 Tiempo promedio en los casos de la línea jurisprudencial descrita.

5 Por tratarse de una conducta agravada por el hecho de que la conducta recaiga en una mujer, conforme al artículo 229 inciso 2 del CP

6 Artículo 111 y 112 inciso 1 del CP

7 Título II de la ley 294 de 1996 
no consultó la teoría de género para excluir a las mujeres8 del núcleo familiar que tienen con sus exparejas, ni las necesidades y afectaciones de estas víctimas de violencia de género, menos la política criminal, ni las causas y consecuencia de este tipo de conductas. Abriendo también una ventana para que en posteriores casos, ya no solo en relación con las exparejas, se resuelva afectaciones al núcleo familiar con similares argumentos simplistas de límite espacial de convivencia, por ejemplo, podría llegar a afirmarse que los cónyuges o compañeros permanentes que, manteniendo una relación a distancia, por diferentes circunstancias, por el hecho de no convivir constantemente bajo el mismo techo, de presentarse un maltrato entre ellos, no se configure una violencia intrafamiliar, porque la familia que se protege con este punible es la concreta que se limita a la convivencia pacífica bajo el mismo techo.

Adicional a lo anterior, resulta una prueba más de los argumentos de la Corte que generan violencia de género el hecho de que haya desaprovechado una oportunidad en el 2006 de zanjar este asunto definitivamente con el argumento de autoridad que expuso, y posteriormente haya omitido contra argumentar este postulado en el 2017. Ha debido profundizar el argumento de autoridad legislativo que la misma Sala trajo a colación en el 2006, de las justificaciones del tipo penal de violencia intrafamiliar, en las que se dijo que se buscaba reprimir conductas ilícitas al "interior de la relación familiar o como consecuencia de haber existido una relación familiar", postulado que hubiera permitido enriquecer la discusión sin necesidad de acudir a estereotipos que limitan a la mujer a su condición de madre ni a la protección de los derechos de los hijos, cuando se quiere discutir en juicio solo el maltrato entre sus padres y menos a argumentos simplistas de la protección según características espaciales de convivencia. Con este argumento de autoridad resultaba fácil, por decirlo de alguna manera, interpretar que para el propósito del legislador que introdujo a nuestro sistema jurídico la conducta punible de violencia intrafamiliar, era intrascendente si para el momento de los hechos la pareja convivía, o tenían hijos comunes, pues el espíritu de la norma era proteger también a las personas que habiendo conformado una familia -en alguna épocafueran víctimas de maltrato originado por esa relación familiar anterior, asunto que volvería este problema ya no un debate doctrinal o hermenéutico, sino probatorio, y que protegería a la mujer que con mucho esfuerzo ha dado el primer paso para empoderarse, terminar la relación con su abusador y separarse físicamente de él.

Finalmente, si los razonamientos basados en teoría de género antes expuestos no fueran suficientes para reprocharle a la Corte, propone argumentos que se caen por su propio peso. Sostiene que como la Constitu-

8 A lo largo del artículo se refiere como víctimas del maltrato a las exparejas a las mujeres, por cuanto según las estadísticas recolectadas y citadas en este texto, en su gran mayoría, las mujeres son las vulneradas por este punible. 
ción protege la conformación libre de familia, por la misma autonomía de la voluntad puede terminarse, pero como vemos en la ausencia de la posibilidad de divorcio unilateral, esa premisa ni siquiera es válida en el derecho civil personas, para los cónyuges, así que el argumento se cae al promover una afirmación que generaliza circunstancias familiares que resultan especiales en cada caso en particular, en las que en muchas ocasiones se mantiene la relación familiar, pese a su deseo de terminar el vínculo. Igualmente presenta como contra argumento de la jurisprudencia antes vigente, que la noción de "núcleo familiar" no puede fundarse en el derecho de los niños a tener una familia y no ser separados de ella porque según la Corte impediría el divorcio o separación, lo cual constituye una falacia del tipo "hombre de paja", ya que la Sala Plena de la Corte Suprema de Justicia en sus providencias de 2006 y 2008 sobre el tema, nunca afirmó que cuando se amparaba con el tipo de violencia intrafamiliar el maltrato entre los padres exparejas, porque se mantenía el núcleo familiar, eso significaba que los padres no podían separarse o divorciarse, por el contrario, se indicó que esa inclusión se hacía precisamente en razón a la que los hijos son más vulnerables a afectaciones psicológicas -según dicha providencia- cuando sus padres se separan o divorcian. Además, fundamenta su tesis en la modificación al artículo 229 del CP, con el artículo 33 de la Ley 1142 de 2007, que permite la configuración del injusto por una persona que "no siendo miembro del núcleo familiar, sea encargado del cuidado de uno o varios miembros de una familia en su domicilio", porque sostiene que la misma ley trata de situar el ilícito dentro de los límites de la residencia que comparte el núcleo familiar; argumento que pierde peso si tenemos en cuenta que este apartado normativo fue modificado el 19 de julio de 2017, con el artículo 3 de la ley 1850 de 2017 para derogar precisamente este límite espacial, dando el legislador el mensaje contrario al del Alto Tribunal.

Como un punto a resaltar que pudiera tenerse en cuenta para otra investigación sería el del estudio de las causas y consecuencias de la despenalización del punible de violencia intrafamiliar. Frente a lo cual considero que desde un punto de vista de justicia restaurativa, estaría de acuerdo en cierto grado, pero no como lo ha querido proponer la rama legislativa, ni como parece que lo está apoyando la Corte Suprema de Justicia: un simple cambio de interpretación del tipo con la finalidad de ignorar el problema social, pues insisto, el sistema penal acusatorio no produce una solución al conflicto familiar. Por el contrario lo tiende a agravar, pero una solución sí podría darse con el uso de justicia restaurativa, en los casos en que los afectados voluntariamente quieran probar una forma en la que de la mano de políticas sociales, de asistencia psicosocial y técnica para las víctimas, victimarios y sus familias, puedan intentar acordar formas que permitan la recomposición de sus relaciones familiares rotas. Aplicación que sería complicada, demorada y en algunas ocasiones frustrante, pero tendría mejores resultados que una revictimización y pena de prisión. 


\section{REFERENCIAS BIBLIOGRÁFICAS}

Ágreda Benavides, A., y López García, M. D. (2017). Dinámica relacional violenta en ex parejas heterosexuales, en proceso de denuncia penal por violencia intrafamiliar. (Tesis de Maestría en Familia) Obtenido de:http://vitela.javerianacali.edu.co/bitstream/handle/11522/10155/Din\%C3\%A1mica_relacional_violenta.pdf?sequence $=1$ \&isAllowed $=y$ el 19 de séptiembre de 2018. Pontificia Universidad Javeriana, Bogotá D. C., Colombia.

Comesaña Santalices, G. M. (2004). La ineludible metodología de género. Red Revista Venezolana de Ciencias Sociales, UNERMB, Vol.8 $\mathrm{N}^{\circ} 1$ 2004. Obtenido de: https://ebookcentral.proquest.com/lib/ unabsp/detail.action?docID=3168313 el 23 de septiembre de 2018 .

Contretas, M. I. (2014, diciembre) Estado del arte de la violencia intrafamiliar en Colombia: estudios socio jurídicos. Revista de Derecho Público $\mathrm{N}^{\circ} 33$ julio-diciembre de 2014. Universidad de los Andes, Bogotá, D. C., Colombia. 1-29. Obtenido de: http://dx.doi. org/10.15425/redepub.33.2014.24 el 12 de agosto de 2018.

Espinar Ruiz, E. (2003) Violencia de género y procesos de empobrecimiento. Estudio de la violencia contra las mujeres por parte de su pareja o ex - pareja sentimental. (Tesis de doctorado de la Facultad de Ciencias Económicas y Empresariales de la Universidad de Alicante). Obtenido de: https://rua.ua.es/dspace/bitstream/10045/9905/1/Espinar-Ruiz-Eva.pdf el 15 de octubre de 2018. Universidad de Alicante, España.

Exp. No 559. (Corte Suprema de Justicia, Sala de Casación Penal. Auto del 22 de enero de 1998.) No disponible en Relatoría de la Sala de Casación Penal, en su totalidad.

Exp. $\mathrm{N}^{\circ}$ 11-001-02-30-0007-2005-00032. (Corte Suprema de Justicia, Sala Plena. Auto del 23 de marzo de 2006.) No disponible en Relatoría de la Sala de Casación Penal, ni Relatoría de Sala de Tutelas, en su totalidad.

Exp. No 11-001-02-30-000-2008-00333-00. (Corte Suprema de Justicia, Sala Plena. M.P. RUTH MARINA DÍAZ RUEDA. Auto del 28 de agosto de 2008).

Facio Montejo, A. (1992). Cuando el género suena: cambios trae. Una metología para el análisis de género del fenomeno legal. ILANUD 1era edición. San José, Costa Rica, 1992. Obtenido de: http://www. fiscalia.gub.uy/innovaportal/file/2477/1/libro.pdf el 24 de septiembre de 2018.

FACIO MONTEJO, A. (2002). Con los lentes de género se ve otra justicia. Revista EL OTRO DERECHO, número 28, julio 2002. ILSA Bogotá. Obtenido de: http://sitios.te.gob.mx/genero/media/pd- 
f/562cc59475f0864.pdf el 23 de septiembre de 2018.

Gómez Ortíz, O., Martín, L., \& Ortega Ruiz, R. (2017). Conflictividad parental, divorcio y ansiedad infantal. Revista Pensamiento Psicológico, Vol $15 \mathrm{~N}^{\mathrm{o}}$ 2, 2017, pp 67-78. Obtenido de: http://www. scielo.org.co/pdf/pepsi/v15n2/v15n2a06.pdf el 20 de septiembre de 2018.

Instituto Nacional de Medicina Legal y Ciencias Forenses (2016). Boletín Epidemiológico. Violencia de género en Colombia. Análisis comparativo de las cifras de los años 2014, 2015 y 2016. Obtenido de: http://www.medicinalegal.gov.co/documents/20143/57985/ Violencia + de + G\%C3\%A9nero+en + Colombia. + An\%C3\%A1lisis + comparativo + de +las + cifras + de +los +a\%C3\%B1os +2014\%$2 \mathrm{C}+2015+\mathrm{y}+2016$.pdf el 13 de septiembre de 2018 .

Instituto Nacional de Medicina Legal y Ciencias Forenses (2017). Violencia contra las mujeres. Colombia, comparativo años 2016 y 2017 (enero a octubre). Obtenido de: http://www.medicinalegal.gov.co/ documents/20143/57992/Violencia+contra+las+mujeres.pdf el 13 de septiembre de 2018 .

Marchiori, H. (2010). SERIE VICTIMOLOGÍA 8. VIOLENCIA FAMILIAR-CONYUGAL. Obtenido de: https://ebookcentral.proquest. com/lib/unabsp/detail.action? docID=3189184\# el 12 de septiembre de 2018.

Organización Muncial de la Salud. Organización Panamericana de la Salud. (2013). Comprender y abordar la violencia contra las mujeres. Violencia infligida por la pareja. Obtenido de: http://apps.who.int/ iris/bitstream/handle/10665/98816/WHO_RHR_12.36_spa.pdf;jsessionid =F9F5CABB992B02E273B1C9B̄8519 $\bar{B} 8072$ ? sequen$\mathrm{ce}=1$ el 21 de septiembre de 2018.

Rad. 48047. (Corte Suprema de Justicia, Sala de Casación Penal. SP80642017. M.P. LUIS ANTONIO HERNANDEZ BARBOSA. Sentencia del 7 de junio de 2017).

Rad. 50775. (Corte Suprema de Justicia, Sala de Casación Penal. SP206072017. M.P. EUGENIO FERNÁNDEZ CARLIER. Sentencia del 6 de diciembre de 2017).

Rad. 49956. (Corte Suprema de Justicia, Sala de Casación Penal. SP206122017. M.P. FERNANDO ALBERTO CASTRO CABALLERO. Sentencia del 6 de diciembre de 2017).

Rad. 50274. (Corte Suprema de Justicia, Sala de Casación Penal. AP0962018. M.P. LUIS GUILLERMO SALAZAR OTERO. Auto del 17 de enero de 2018).

Rad. 51956. (Corte Suprema de Justicia, Sala de Casación Penal. AP1312-2018. M.P. EUGENIO FERNÁNDEZ CARLIER. Auto del 4 de abril de 2018). 
Rad. 46784. (Corte Suprema de Justicia, Sala de Casación Penal. SP9692018. M.P. EUGENIO FERNÁNDEZ CARLIER y LUIS ANTONIO HERNÁNDEZ BARBOSA. Sentencia del 4 de abril de 2018).

Rodríguez Luna, R. (2015). Culpa, miedo y vergüenza: las emociones de la violencia. El caso de violencia contra la pareja y/o ex - pareja. Revista Derechos y Libertades, (33), 223-252. https://doi-org.aure. unab.edu.co/10.14679/1017 el 15 de octubre de 2018 .

Superintendencia de Notariado y Registro. (2017, 20 de abril). EN COLOMBIA, POR CADA TRES MATRIMONIOS HAY UN DIVORCIO. Obtenido de: https://www.supernotariado.gov.co/ PortalSNR/ShowProperty? nodeId =\%2FSNRContent\%2FWLSWCCPORTAL01149611\%2F\%2FidcPrimaryFile\&revision=latestreleased el 13 de septiembre de 2018.

Torres Romero, S. (2013). Aproximación al fenómeno de la retractación en las causas de violencia intrafamiliar. Revista de Derecho (Valdivia), Universidad Austral de Chile. Vol XXVI, No1, julio 2013, pp.167-180. Obtenido de: http://www.redalyc.org/articulo. oa? $\mathrm{id}=173728674008$ el 20 de septiembre de 2018 .

Zaldívar Cerón, A., Gurrola Peña, G. M., Balcázar Nava, P., Moysén Chimal, A., \& Esquivel Santoveña, E. E. (2015). Las mujeres separadas de cara a la violencia de sus exparejas. Rumbo a su caracterización. Revista CienciaUAT, ciencias sociales Vol 10 No 1, jul-dic 2015, pp 8392. Obtenido de: http://www.scielo.org.mx/pdf/cuat/v10n1/20077858-cuat-10-01-00083.pdf el 20 de septiembre de 2018. 